Jeвв, W. H. H. \& Tomlinson, A. H. (1951). J. gen. Microbiol. 5, 951-965.

\title{
The Catabolic Activity of Washed Suspensions of Haemophilus pertussis
}

\author{
BY W. H. H. JEBB and A. H. TOMLINSON \\ Public Health Laboratory, Oxford
}

\begin{abstract}
SUMMARY: Washed suspensions of a laboratory strain of Haemophilus pertussis did not take up oxygen with, or ferment, five carbohydrates, nor did the same strain produce detectable acid from fourteen carbohydrates during growth. Of twenty-one amino-acids tested only proline, serine, alanine, aspartic and glutamic acids were oxidized by washed suspensions at an appreciable rate. The first four of these were oxidized to completion but with glutamic acid only $80 \%$ of the theoretical uptake of oxygen occurred; however, in the presence of dinitrophenol it, too, was oxidized to completion. Cells oxidizing glutamic acid in the presence of arsenite produced $\alpha$-ketoglutaric acid.

During the logarithmic growth of $\boldsymbol{H}$. pertussis glutamic acid disappeared from Cohen $\&$ Wheeler's medium. The organism grew in a Cohen $\&$ Wheeler's medium in which the Casamino acids had been replaced by glutamic acid. These results suggest that glutamic acid can serve as energy, carbon and nitrogen source for $\boldsymbol{H}$. pertussis.

Some of the findings were confirmed with freshly isolated strains.
\end{abstract}

Haemophilus pertussis was included in the genus Haemophilus by Winslow, Broadhurst, Buchanan, Krumwiede, Rogers \& Smith (1920) because of a supposed dependence for growth on blood, or other body fluids. Later work has disproved this and tends to separate $H$. pertussis from other members of the genus. $H$. pertussis does not require $X$ or $V$ factors (Rivers, 1922 $a, b$; Fildes, 1923). Hornibrook (1939) grew it in a mixture of casein hydrolysate, an organic sulphur compound (cystine or glutathione), inorganic salts and starch. Later (Hornibrook, 1940) he simplified the medium to a defined mixture of amino-acids, salts, starch and nicotinic acid. Using a modification of Hornibrook's medium, Farrell \& Taylor (1945) noted that some strains required thiamine as well as nicotinic acid and others would not grow without liver extract. Pollock (1949) also noted that defined media would not support the growth of small inocula without yeast extract.

Dawson, Farnworth, McLeod \& Nicholson (1951) found that of a number of amino-acids added to Bordet \& Gengou's medium, aspartic and glutamic acids tended to stimulate growth and serine to inhibit it.

Pollock (1947), using a trained strain, traced the function of blood in media for $H$. pertussis to the ability of serum albumin to bind traces of unsaturated fatty acids, which are toxic to the organism. He found that starch and charcoal, which also bind unsaturated fatty acids, could replace serum albumin. Further, he showed (Pollock, 1949) that his strain actually produced toxic fatty acids during growth in defined media.

Little is known of the metabolic activities of $H$. pertussis, but the following facts appear significant:

(i) Its growth is favoured by adequate aeration (Bordet \& Gengou, 1907; 
Hornibrook, 1939; Wilson, 1945; Farrell \& Taylor, 1945; Cohen \& Wheeler, 1946; and Verwey, Thiele, Sage \& Schuchardt, 1949), though Ungar, James, Muggleton, Pegler \& Tomich (1950) claim that agitation depresses the growth of virulent strains.

(ii) It does not produce acid from sugars (Stillman \& Bourn, 1920; Rivers, $1922 b$; Lawson, 1939).

(iii) Various workers report that the medium becomes alkaline during growth, suggesting a vigorous metabolism of amino-acids, and Ungar et al. (1950) state that during 15 days' growth $\boldsymbol{H}$. pertussis completely removed from the medium glutamic and aspartic acids, serine, glycine and proline.

It seems probable, therefore, that $H$. pertussis obtains its energy for growth by aerobic metabolism of amino-acids. The oxidative metabolism of the organism has been studied in an attempt to determine its principal sources of energy and carbon as a preliminary to further investigations of its nutrition and the role of unsaturated fatty acids.

\section{METHODS}

Organisms. Strains 318, 723, 724 and 1437 were isolated in this laboratory and had been kept dried for 2 years prior to use. Strain 2916 was kindly supplied by Mr A. F. B. Standfast. A cellar of dried cultures was prepared by Stamp's (1947) method, and a fresh tube was opened monthly and maintained on Bordet \& Gengou's medium. Periodic tests showed that the strains were always agglutinated by Phase I serum (from the Standards Laboratory) at a dilution of $1 / 16,000$ and frequently by $1 / 32,000$. Towards the end of the investigation a virulence test on strain 724 was performed by $\mathrm{Mr}$ A. F. B. Standfast, of The Lister Institute of Preventive Medicine, Elstree. He found that the LD 50 on the 28 th day, for mice inoculated intranasally, was $3.6 \times 10^{6}$, i.e. group B (Standfast, 1951) and stated that the strain was of moderate to high virulence.

Some of the findings were confirmed with fresh strains.

Media. Bordet \& Gengou's medium was prepared according to the method given by Mackie \& McCartney (1948).

Two liquid media were used. Most of the work was done with Cohen \& Wheeler's (1946) medium prepared as described by them, but Distillers Co. Ltd. pressed yeast was used to prepare the dialysate. Difco Casamino acids were obtained from Messrs Baird and Tatlock Ltd. The medium was distributed in $100 \mathrm{ml}$. lots in $500 \mathrm{ml}$. Erlenmeyer flasks. Some of the earlier experiments were done with a modification (designated medium VI) containing an acid hydrolysate of casein (Gladstone \& Fildes, 1940) in place of Casamino acids. The medium was distributed in Roux bottles.

Washed suspensions. Inocula for the flasks were prepared by scraping growth off Bordet \& Gengou's medium and suspending it in medium to a standard opacity. Plate counts were occasionally performed and showed that the inoculum used contained approximately $10^{9}$ viable cells per flask. Roux bottles of medium VI were grown for 3 days, and flasks of Cohen \& Wheeler's medium were incubated on a mechanical shaker for $22 \mathrm{hr}$., both 
at $35^{\circ}$. The cells were centrifuged from the medium, washed twice with distilled water and resuspended in water. Using a Hilger 'Biochem' absorptiometer a calibration curve was constructed relating extinction to the dry weight of cells. Because of the marked decrease in respiration when they were washed, cells from medium VI were suspended in $5 \%$ yeast dialysate prepared by the method described by Cohen \& Wheeler (1946).

Ammonia determinations. Samples were acidified at the time of collection and subsequently distilled with soda in the apparatus described by Markham (1942). A few drops of tri-amyl citrate were added to prevent frothing. The ammonia was distilled into $2 \%(\mathrm{w} / \mathrm{v})$ boric acid and titrated with $0.01 \mathrm{~N}$ hydrochloric acid. In some experiments the ammonia was estimated with Nessler's reagent (Johnson, 1941).

Gas exchanges were measured by conventional Warburg methods as described by Umbreit, Burris \& Stauffer (1945). Except where otherwise stated, each manometer flask contained: cell suspension, $1.0 \mathrm{ml}$.; $0.2 \mathrm{M}$ phosphate buffer ( $\mathrm{pH} \mathrm{7.6}$ ), $0.5 \mathrm{ml}$.; substrate, $0.2 \mathrm{ml}$.; water, $0.3 \mathrm{ml}$.; and $10 \%$ potash, $0 \cdot 1 \mathrm{ml}$., in the centre well. The flasks were shaken at $120 \mathrm{osc} . / \mathrm{min}$. with a $3 \mathrm{~cm}$. stroke in a bath at $37^{\circ}$.

Glutamate estimations were performed by Gale's (1945) method as modified by Krebs (1948).

Substrates. We are indebted to various members of the University Biochemistry Department for samples of D-glutamic acid, L-serine and sodium pyruvate. The other amino-acids used were commercial preparations obtained from British Drug Houses Ltd., Roche Products Ltd. and L. Light \& Co. Ltd.; sodium lactate was prepared from 'Analar' lactic acid; $\alpha$-ketoglutaric and oxaloacetic acids were obtained from Light \& Co. Ltd.

\section{RESULTS}

\section{Fermentation of carbohydrates during growth}

Five strains were inoculated into $10 \mathrm{ml}$. lots of medium VI containing $1 \%(\mathrm{w} / \mathrm{v})$ of glucose, fructose and maltose in $100 \mathrm{ml}$. conical flasks. The flasks were then incubated at $35^{\circ}$ without shaking for 5 days, and the $\mathrm{pH}$ of each flask was measured. In every case the $\mathrm{pH}$ had risen from the initial value of $7 \cdot 2$ to 8.0-8.4. In another experiment strain 724 was inoculated into $10 \mathrm{ml}$. lots of Cohen \& Wheeler's medium containing $1 \%(\mathrm{w} / \mathrm{v})$ of the sugar to be tested in $100 \mathrm{ml}$. conical flasks and in $6 \times \frac{3}{4}$ in. tubes. The initial $\mathrm{pH}$ was $6 \cdot 8-7 \cdot 2$, and after 5 days' incubation at $35^{\circ}$ without shaking it had risen, in every case, to 8.0-8.4. After a further 5 days there was no change. The 'sugars' tested in this experiment were glucose, fructose, galactose, lactose, sucrose, glycerol, adonitol, arabinose, rhamnose, mannitol, dulcitol, sorbitol, maltose and raffinose.

\section{Oxidation and fermentation of carbohydrates by washed suspensions}

Cells were grown on Cohen \& Wheeler's medium, washed suspensions prepared from them as previously described and the oxygen uptake with 
glucose, maltose, sucrose, lactose and starch was measured in Warburg flasks. The anaerobic production of carbon dioxide from these five carbohydrates was also measured in Warburg flasks. The oxygen uptake and carbon dioxide output with these five substances were not materially different from the blank rates. From this experiment, combined with the preceding results during growth, it would appear that, even if these carbohydrates are attacked, they are unlikely to provide the main source of energy for growth.

\section{Production of ammonia during growth}

Preliminary experiments showed that the rise of $\mathrm{pH}$ of the medium during growth of $\boldsymbol{H}$. pertussis was accompanied by the production of ammonia. Flasks (250 ml. capacity) containing $50 \mathrm{ml}$. of medium VI were inoculated with five strains of $H$. pertussis. The flasks were incubated unshaken at $35^{\circ}$, and samples were removed daily for estimation of turbidity and for ammonia determination. All the strains increased the ammonia content of the medium by about $5 \mu \mathrm{mol} . / \mathrm{ml}$. in 4 days, the rise being roughly parallel with the growth.

\section{Oxidation of amino-acids}

As $H$. pertussis grows best in well-aerated culture it seemed justifiable to investigate the respiration of resting suspensions of organisms and to see which amino-acids, if any, were oxidized by washed cells. Cells were grown in medium VI, washed twice with water, resuspended in $5 \%$ yeast dialysate, and put up to oxidize the amino-acids which Ungar et al. (1950) found to be removed from the medium. The results are shown in Table 1 . With the exception of glycine, all the substrates increased the oxygen consumption and ammonia production. The uptake with medium VI was equal to that with glutamic acid during the first hour, but thereafter it fell off, which suggests that the oxidation of the medium may be largely due to its glutamic acid content.

Table 1. Oxidation of five amino-acids by strain 724

\begin{tabular}{|c|c|c|c|c|c|c|c|}
\hline \multirow[t]{2}{*}{ Substrate ... } & Nil & Medium VI & $\begin{array}{l}\text { L-Glutamic } \\
\text { acid }\end{array}$ & $\begin{array}{c}\text { DL-Aspartic } \\
\text { acid }\end{array}$ & Glycine & DL-Serine & DL-Proline \\
\hline & \multicolumn{7}{|c|}{ Oxygen uptake $(\mu \mathrm{l})}$. \\
\hline 60 & 56 & 208 & 212 & 74 & 40 & 76 & 110 \\
\hline 120 & 73 & 307 & 462 & 118 & 61 & 121 & 187 \\
\hline 180 & 82 & 357 & 721 & 148 & 71 & 146 & 236 \\
\hline 210 & 86 & 374 & 852 & 156 & 76 & 157 & 280 \\
\hline $\begin{array}{l}\mu \text { mol. ammonia } \\
\text { produced in } \\
210 \text { min. (blanks } \\
\text { subtracted) }\end{array}$ & $1 \cdot 0$ & $3 \cdot 5$ & $10 \cdot 0$ & $3 \cdot 0$ & $1 \cdot 0$ & $\mathbf{3} \cdot \mathbf{8}$ & $\mathbf{2 \cdot 5}$ \\
\hline
\end{tabular}

Cells from medium VI made up in $5 \%$ yeast dialysate to contain $5 \cdot 4 \mathrm{mg} . / \mathrm{ml}$.

Oxygen uptake with all the other amino-acids that were available was then investigated. With washed suspensions the following amino-acids did not give oxygen uptakes appreciably higher than the blank: DL-valine, L-tryptophan, L-arginine, L-lysine, L-hydroxyproline, DL-leucine, DL-isoleucine, DL-norleucine, 
DL-methionine, DL-threonine, DL-norvaline, DL-phenylalanine, L-histidine, $\beta$-alanine and L-tyrosine. With D-glutamic acid and DL- $\alpha$-alanine the $\boldsymbol{Q}_{\mathbf{o}_{\mathbf{2}}}$ was approximately one-seventh of that with L-glutamic acid.

To test whether incorporating extra amino-acid in the growth medium would increase the rate of oxidation by washed cells proline, glycine, alanine and aspartic acid were added to four lots of Cohen \& Wheeler's medium to give a final concentration of $0.025 \mathrm{M}$ and strain 724 was grown in these media. The rate of oxidation of proline by proline-grown cells was $25 \%$ higher than by cells out of the ordinary medium. The rate of oxidation of the other three acids was not increased by growth in the fortified media.

The effect of varying the period of growth before harvesting the cells was investigated by inoculating several flasks of Cohen \& Wheeler's medium with strain 724 and preparing washed suspensions after 12, 18, 23 and $39 \mathrm{hr}$. growth. The rates of oxidation of glutamic acid, proline, serine and alanine, did not alter greatly between 12 and $23 \mathrm{hr}$., but by $39 \mathrm{hr}$. they had all declined to varying degrees. With aspartic acid, the cells showed little activity and this declined steadily from 12 to $39 \mathrm{hr}$. The results were confirmed with cells grown in $800 \mathrm{ml}$. medium in a Winchester bottle from which samples were removed for turbidity readings and the preparation of washed suspensions. As the growth was logarithmic up to $23 \mathrm{hr}$. the enzymes oxidizing these five aminoacids were most active in growing cells. The slow oxidation of aspartic acid will be discussed more fully later.

As the work had so far all been done with strain 724, the respiration of four other dried strains and five freshly isolated strains was investigated to see whether strain 724 was typical. The results given in Table 2 show that strain 724 behaved in the same way towards the substrates as the other strains examined.

\section{Detailed investigation of amino-acid metabolism}

Effect of $\mathrm{pH}$ on the oxidation of glutamic acid. Strain 724 was grown in Cohen \& Wheeler's medium, suspended in distilled water and put into Warburg flasks over a $\mathrm{pH}$ range from $8 \cdot 2$ to $4 \cdot 5$. The activity in phosphate buffer varied little between $\mathrm{pH} 8.2$ and 6.9. Cells in borate buffer at $\mathrm{pH} 8.0$ were much less active than cells in phosphate buffer; higher $\mathrm{pH}$ values were not investigated.

The effect of yeast dialysate on glutamic acid oxidation. Cells grown in medium VI lost a large part of their activity during washing and this activity was restored by adding yeast dialysate to the manometer flasks. Even after subtracting the increased blank some $50 \%$ stimulation of the respiration in glutamic acid remained. The yeast dialysate could not be replaced by a mixture of $\mathbf{B}$ vitamins, including biotin and pyridoxal phosphate. Cells grown in Cohen \& Wheeler's medium did not show the stimulation by yeast dialysate, nor suffered any reduction in their activity by dilution of the cell suspension The matter was not pursued further at this point.

The relation between glutamic acid oxidized and the amount of oxygen taken up. The amount of oxygen taken up per mol. glutamic acid consumed was next 


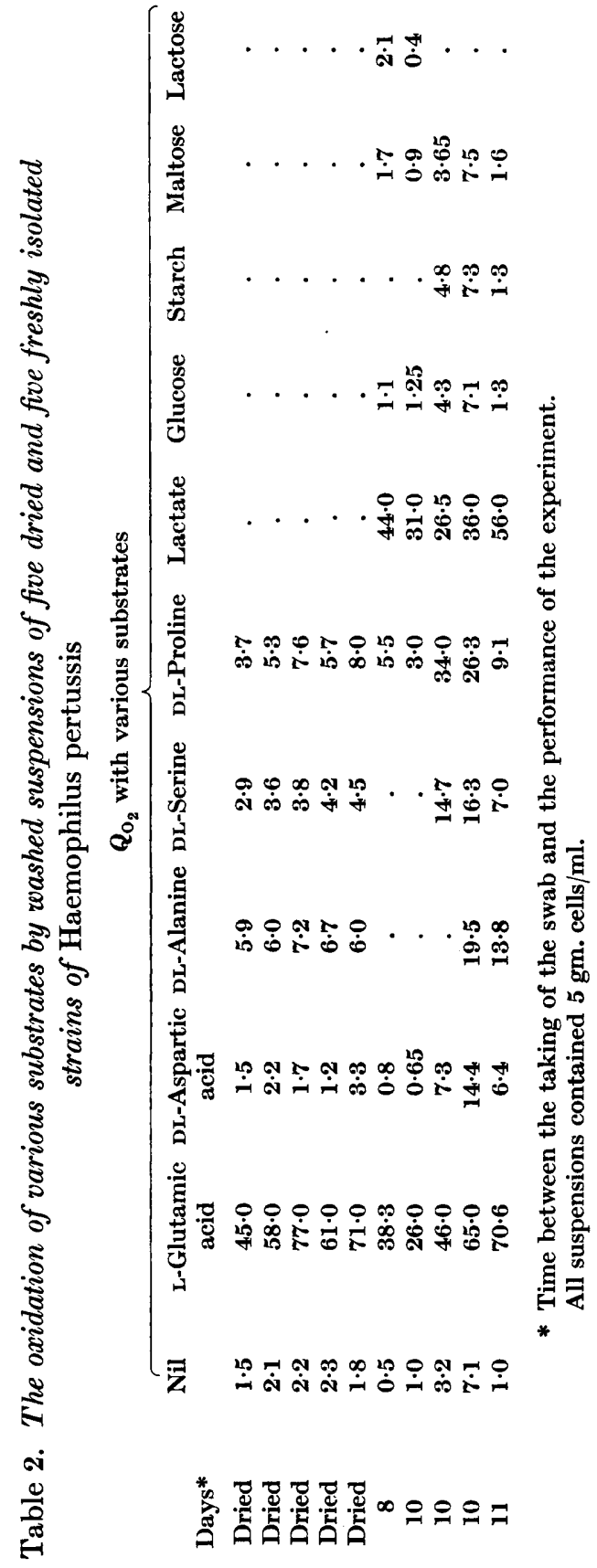

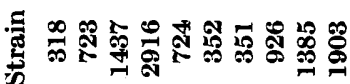

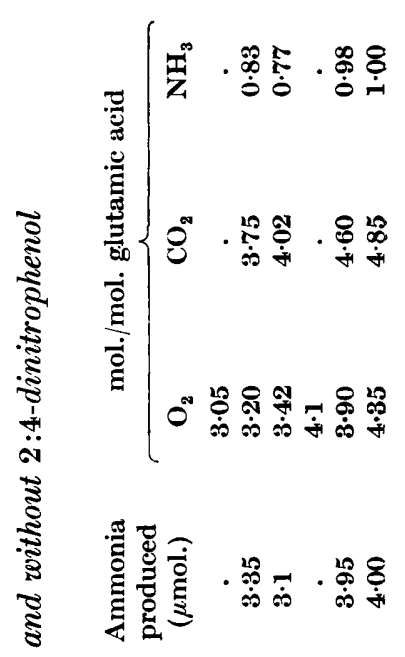

莡

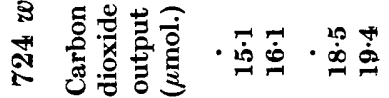

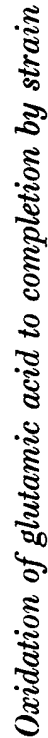
$\dot{8}$ $\stackrel{0}{\frac{0}{0}}$

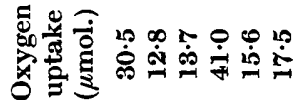

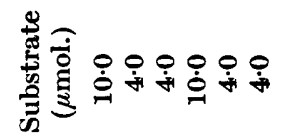

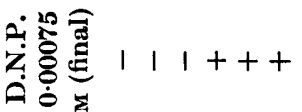

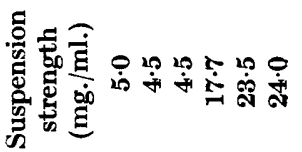

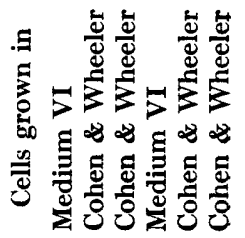
这富- 
investigated. Klein (1940) concluded that $H$. parainfluenzae oxidized glutamic acid thus:

$$
\mathrm{C}_{5} \mathrm{H}_{9} \mathrm{NO}_{4}+2 \cdot 5 \mathrm{O}_{2}=\mathrm{CH}_{3} \mathrm{COOH}+\mathrm{H}_{2} \mathrm{O}+3 \mathrm{CO}_{2}+\mathrm{NH}_{3} \text {. }
$$

Complete oxidation of glutamic acid would require $4.5 \mathrm{~mol}$. of oxygen per mol. glutamic acid, thus:

$$
\mathrm{C}_{5} \mathrm{H}_{9} \mathrm{NO}_{4}+4 \cdot 5 \mathrm{O}_{2}=3 \mathrm{H}_{2} \mathrm{O}+5 \mathrm{CO}_{2}+\mathrm{NH}_{3} \text {. }
$$

Using $10 \mu \mathrm{mol}$. glutamic acid in each flask it was shown that rather over 3 mol. oxygen were taken up per mol. glutamic acid (Table 3, Exp. 1). The yield of carbon dioxide and ammonia were then measured in parallel with the oxygen uptake (Table 3, Exps. 2 and 3). As $20 \%$ of the carbon was not accounted for, an attempt was made to detect volatile acids at the end of glutamic acid oxidation.

Strain 724 was grown in Cohen \& Wheeler's medium and the washed cells were put up in eight manometer flasks, each containing $10 \mu \mathrm{mol}$. glutamic acid. A blank reaction mixture equal to the contents of the eight flasks was put up in a $100 \mathrm{ml}$. conical flask on a shaker in the incubator. When the respiration had ceased the contents of the manometer flasks were pooled, the flask contents and the blank reaction mixture were acidified with $2 \mathrm{ml}$. 4i $\mathrm{N}$ sulphuric acid and $2 \mathrm{ml} .20 \%(\mathrm{w} / \mathrm{v})$ sodium tungstate added. After filtration and washing of the precipitate, the combined filtrates and washings were steam-distilled in the Markham apparatus. The distillate $(150 \mathrm{ml}$.) was collected and titrated with $0.02 \mathrm{~N}$ soda in a $\mathbf{C O}_{2}$-free atmosphere. In a series of four experiments a mean value of $\mathbf{0 . 0 3 5}$ equivalent of acid were recovered for each mol. of glutamic acid oxidized. As this quantity was not considered to be significant and the discrepancies between the observed and calculated figures for oxygen, carbon dioxide and ammonia were too great to be ascribed to experimental error, it seemed probable that oxidative assimilation was occurring and the possibility of inhibiting this was considered.

2:4-Dinitrophenol, widely used for uncoupling assimilation from oxidation (Clifton, 1946), did in fact increase the total oxygen taken up per mol. glutamic acid consumed. As it also decreased the rate of respiration a stronger cell suspension was used. Table 3, Exp. 4, shows that in the presence of 2:4-dinitrophenol $4 \cdot 1 \mathrm{~mol}$. oxygen were taken up for each mol. glutamic acid used. Table 3, Exps. 5 and 6, shows the oxygen uptake and production of carbon dioxide and ammonia from glutamic acid by cells of $\boldsymbol{H}$. pertussis poisoned with 2:4-dinitrophenol. The observed ratios compared favourably with the theoretical ratios for complete oxidation.

The course of the reaction. Having shown that $H$. pertussis oxidized glutamic acid completely, it was of interest to see what possible intermediates were oxidized at a similar rate, in particular the substances postulated by Klein as intermediates in the oxidation of glutamic acid by $\boldsymbol{H}$. parainfluenzae. A washed suspension of strain 724 was put up in a Warburg respirometer to oxidize all the available acids with one to five carbon atoms. Lactate and succinate were initially attacked as rapidly as glutamic acid. $\alpha$-Ketoglutarate was oxidized at about $50 \%$ of the rate with glutamate. With oxaloacetate, fumarate, 
malate, propionate, acetate and formate the oxygen uptake did not exceed that of the blank. The oxygen uptake with pyruvate was about $15 \%$ of that with glutamate. The three keto-acids were put up anaerobically with cells suspended in bicarbonate buffer and the carbon dioxide output measured. Only with $\alpha$-ketoglutaric acid did the output exceed that of the blank.

$\alpha$-Ketoglutaric acid is known to be produced from glutamic acid by animal tissue (Krebs, 1933), yeast (Euler, Adler \& Eriksen, 1937) and Bacterium coli (Adler, Hellström, Gunther \& Euler 1938). This reaction was looked for with $\boldsymbol{H}$. pertussis. By using inhibitors which have been successfully employed for blocking the oxidation of keto-acids (toluene, $2: 4$-dinitrophenylhydrazine, nitrite and cyanide), an attempt was made to obtain a quantitive uptake of half a mol. of oxygen. These substances either completely stopped respiration or decreased the respiration in glutamate almost to the level of the blank. Arsenious oxide was more satisfactory. Cell suspensions containing $19 \mathrm{mg}$. dry weight were put into Warburg flasks to oxidize $20 \mu \mathrm{mol}$. L-glutamic acid in the presence of various concentrations of arsenious oxide. The manometers were read for $240 \mathrm{~min}$., taken down and the ammonia estimated. In the absence of inhibitor the oxygen/ammonia ratio in mol. was $3 \cdot 0: 1 \cdot 0$, suggesting that assimilation of the product of deamination was occurring. With $0.001 \mathrm{M}$ arsenious oxide assimilation appeared to be inhibited and the ratio approached the theoretical value for complete oxidation, i.e. 4.5:1·0. As the concentration of inhibitor rose oxygen uptake was more inhibited than ammonia production, but even with $0.01 \mathrm{M}$ arsenious oxide the ratio was $1.5: 1 \cdot 0$, i.e. three times that required for the single step of oxidative deamination.

Isolation of $\alpha$-ketoglutaric acid. Although the reaction could not be completely blocked after the first stage some $\alpha$-ketoglutarate probably accumulated in the presence of arsenious oxide, and an attempt was made to isolate it as a $2: 4$-dinitrophenylhydrazone.

A washed suspension of strain 724 was prepared and the following mixture put up: cell suspension (20 mg./ml.), 10.0 ml.; molar phosphate buffer $\mathrm{pH} \mathbf{7 \cdot 6}$, $1 \mathrm{ml}$.; arsenious oxide $0.05 \mathrm{M}, 2 \mathrm{ml}$.; glutamic acid $0.1 \mathrm{M}, 6.6 \mathrm{ml}$.; and water $0.4 \mathrm{ml}$. This mixture was shaken in the incubator overnight and then the cells were precipitated with trichloroacetic acid and $2 \mathrm{ml}$. of $1 \%(\mathrm{w} / \mathrm{v}) 2$ :4-dinitrophenylhydrazine in $2 \mathrm{~N}$ hydrochloric acid were added. After standing overnight in the cold a small amount of orange-yellow precipitate formed. Control mixtures from which glutamate or arsenious oxide were omitted gave no yellow precipitate.

The products from three experiments were pooled and purified by the method of Weil-Malherbe \& Krebs (1935). The yield was only a few milligrams and it was not possible to recrystallize from ethyl acetate as they had done. Without very careful purification the melting-point was obviously of no help in identifying the compound. Cavallini, Frontali \& Toschi (1949) have described a partition chromatographic method of separating the 2 : 4-dinitrophenylhydrazones of keto-acids and this method was tried on the substance produced by $H$. pertussis. 2:4-Dinitrophenylhydrazones were prepared from known samples of $\alpha$-ketoglutaric acid, oxaloacetic acid and pyruvic acid and 


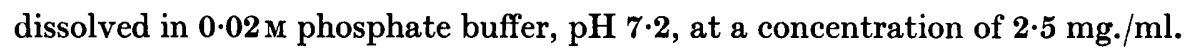
Using a strip of Whatman's no. 1 filter-paper $12 \times 55 \mathrm{~cm}$., and spots containing approximately $20 \mu \mathrm{g}$. of each $2: 4$-dinitrophenylhydrazone satisfactory separation was obtained either in $n$-butanol/water or in $n$-butanol/ammonia. The pyruvate spot moved so much faster than the others that to get adequate separation the solvent front and the pyruvate spot had to run off the end of the paper. Mixtures of the 2:4-dinitrophenylhydrazones of $\alpha$-ketoglutaric acid and oxaloacetic acid were clearly separated into two spots after approximately $60 \mathrm{hr}$. at room temperature with either pair of solvents. The unknown hydrazone was put up alongside the hydrazones of $\alpha$-ketoglutaric acid and oxaloacetic acid. With either solvent the unknown moved as a single spot at the same rate as the hydrazone of $\alpha$-ketoglutaric acid, and it was, therefore, concluded that the hydrazone isolated was that of $\alpha$-ketoglutaric acid.

The oxidation of aspartic acid. When suspensions were put up to oxidize aspartic acid very variable rates of respiration were obtained; frequently the rate was little higher than the blank, but occasionally it was $50 \%$, or more, of the respiration with glutamic acid. Examination of the results of a number of experiments suggested that the higher $Q_{\mathrm{o}_{2}}$ values were given by the denser suspensions and by those put up with least delay after harvesting. To test this, strain 724 was grown as usual, washed, made up into suspensions containing 5 and $15 \mathrm{mg} . / \mathrm{ml}$. and put into the manometer flasks as rapidly as possible. The same suspensions were put up again after $6 \mathrm{hr}$. storage on the bench. While the $Q_{\mathrm{O}_{2}}$ of the stronger suspension declined from 40 to $27 \cdot 6$ that of the weaker suspension fell from $36 \cdot 0$ to $3 \cdot 5$. The activity of the stored weaker suspension was largely restored by the addition of boiled fresh cells and boiled cells added to a weak suspension before storage decreased the deterioration.

The effect of dilution of the cell suspension was investigated by putting up four strengths of suspension to oxidize aspartic acid. Fig. 1 shows that the four suspensions took up 15, 36, 94 and $240 \mu \mathrm{l}$. of oxygen in the first $30 \mathrm{~min}$., which implies that the rates (whether the blanks are subtracted or not) increased out of proportion to the strength of the suspension. These observations show a similarity to the behaviour of the serine deaminase of Bact. coli (Gale \& Stephenson, 1938) and the aspartase II of Bact. coli (Gale, 1938). The phenomenon was not studied further, but by using strong fresh suspensions it was possible to perform the oxygen and carbon balance experiments described later.

The relation between the amount of substrate oxidized and the amount of oxygen taken up from other amino-acids. The amino-acids used in these experiments were L-aspartic acid, L-proline, L-serine and DL-alanine, that is, those aminoacids with which oxygen had been taken up most rapidly in preliminary experiments. Cells of strain 724 were grown in Cohen \& Wheeler's medium, washed twice in distilled water, and put up in Warburg flasks. The total oxygen uptake and carbon dioxide output was measured in each case. The results of these experiments are given in Table 4, from which it can be seen that even in the absence of an assimilation inhibitor the amounts of oxygen taken up and of carbon dioxide evolved with these amino-acids compared 
favourably with the theoretical amounts. In another experiment the theoretical amount of oxygen was taken up with DL-aspartic acid. Both isomers of this amino-acid and of alanine must have been oxidized, whereas with serine and proline only half the theoretical uptake occurred with the DL form

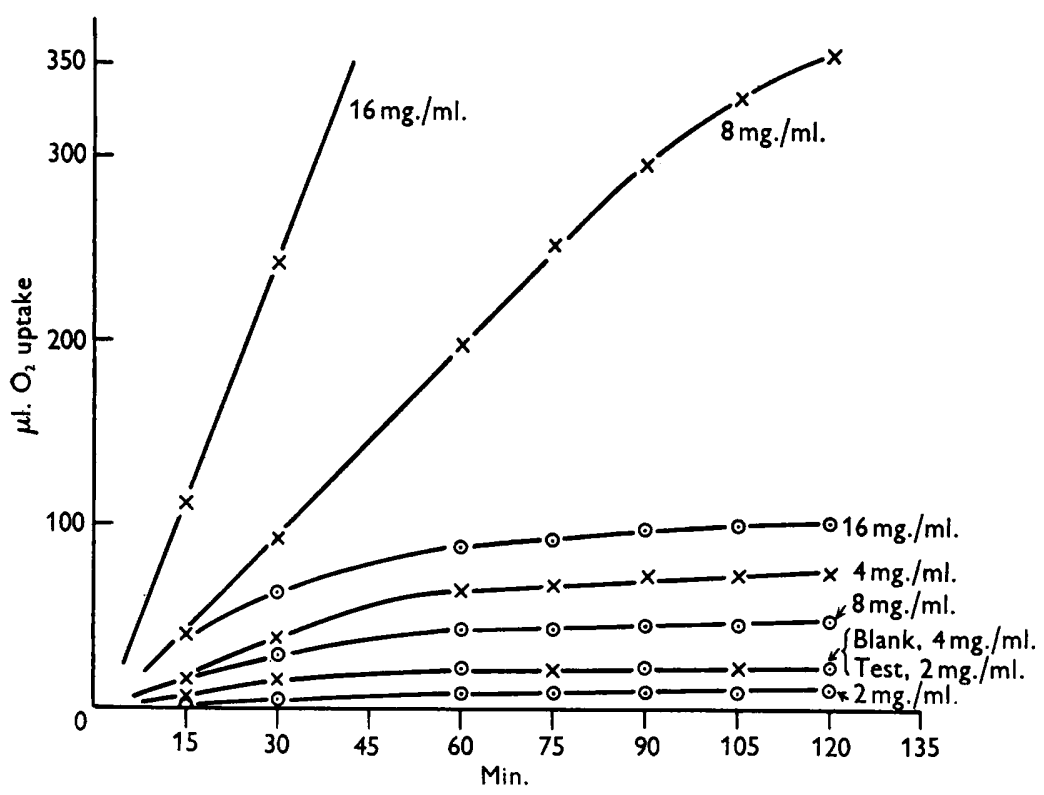

Fig. 1. The oxidation of L-aspartic acid by suspensions of strain 724 of different strengths. $\odot-\odot$, blank; $x-x$, aspartic acid $0.005 \mathrm{~m}$ (final conc.).

Table 4. Oxidation of various amino-acids to completion by strain $\mathbf{7 2 4}$

\begin{tabular}{|c|c|c|c|c|c|c|}
\hline \multirow[b]{2}{*}{ Amino-acid } & \multirow{2}{*}{$\begin{array}{c}\text { Sub- } \\
\text { strate } \\
\text { ( } \mu \text { mol. })\end{array}$} & \multirow{2}{*}{$\begin{array}{c}\mathrm{O}_{2} \\
\text { uptake } \\
(\mu \mathrm{mol} .)\end{array}$} & \multirow{2}{*}{$\begin{array}{c}\mathrm{CO}_{2} \\
\text { output } \\
(\mu \mathrm{mol} .)\end{array}$} & \multirow{2}{*}{$\begin{array}{c}\mathrm{NH}_{3} \\
\text { pro- } \\
\text { duction } \\
(\mu \mathrm{mol} .)\end{array}$} & \multicolumn{2}{|c|}{ Substrate: $\mathrm{O}_{2}: \mathrm{CO}_{2}: \mathrm{NH}_{3}$} \\
\hline & & & & & Observed & Theoretical \\
\hline L-Aspartic acid & $4 \cdot 0$ & $12 \cdot 1$ & $16 \cdot 1$ & $\mathbf{3 \cdot 3 2}$ & $1 \cdot 0: 3 \cdot 02: 4 \cdot 02: 0 \cdot 83$ & $4 \cdot 0: 1 \cdot 0$ \\
\hline L-Proline & $4 \cdot 0$ & $20 \cdot 6$ & $19 \cdot 2$ & $3 \cdot 88$ & $1 \cdot 0: 5 \cdot 15: 4 \cdot 80: 0 \cdot 97$ & $1 \cdot 0: 5 \cdot 5: 5 \cdot 0: 1 \cdot 0$ \\
\hline DL-Alanine & $4 \cdot 0$ & $11 \cdot 1$ & $10 \cdot 6$ & 4.00 & $1 \cdot 0: 2 \cdot 77: 2 \cdot 65: 1 \cdot 00$ & $1 \cdot 0: 3 \cdot 0: 3 \cdot 0: 1 \cdot 0$ \\
\hline L-Serine & $4 \cdot 0$ & $10 \cdot 2$ & $11 \cdot 8$ & $4 \cdot 20$ & $1 \cdot 0: 2 \cdot 54: 2 \cdot 95: 1 \cdot 05$ & $1 \cdot 0: 2 \cdot 5: 3 \cdot 0: 1 \cdot 0$ \\
\hline
\end{tabular}

Cells from Cohen \& Wheeler's medium made up to $20 \mathrm{mg} . / \mathrm{ml}$.

The rate of amino-acid disappearance. By making use of the observed relationships between amounts of oxygen taken up and ammonia formed with each amino-acid it was possible to calculate the rates at which the amino-acids were utilized. To compare the rate calculated from the two measurements a simultaneous determination of oxygen uptake and ammonia production was carried out. In parallel with the Warburg flasks, reaction mixtures were put up in $100 \mathrm{ml}$. conical flasks, which were shaken in the water-bath, and samples were removed for estimation of ammonia by Nessler's method. The results are given in Table 5 in which the $\boldsymbol{Q}$ amino-acid values are calculated from the 
ratios given in Tables 3 and 4 , assuming $3.2 \mathrm{~mol}$. of oxygen and $0.8 \mathrm{~mol}$. of ammonia per mol. of glutamic acid and the theoretical figures for the other acids. In every case the $\boldsymbol{Q}$ value is higher when calculated from the ammonia estimations, and is presumably the more accurate rate for the disappearance of the amino-acid. The rate for aspartic acid is probably low because the necessity for a large crop of cells meant growing the culture for a full $22 \mathrm{hr}$. whereas the aspartic enzyme is more active in younger cells.

Table 5. The rates of amino-acid utilization by strain 724 as measured by oxygen uptake and ammonia production

\begin{tabular}{|c|c|c|c|c|}
\hline Substrate & $\begin{array}{c}\mathrm{O}_{2} \text { uptake } \\
(\mu \mathrm{l} . / \mathrm{hr} .)\end{array}$ & $\begin{array}{c}Q \text { amino-acid } \\
(\mu \mathrm{mol} . / \mathrm{mg} . / \mathrm{hr} .)\end{array}$ & $\begin{array}{l}\mathrm{NH}_{3} \text { production } \\
\quad(\mu \mathrm{mol} . / \mathrm{hr} .)\end{array}$ & $\begin{array}{c}Q \text { amino-acid } \\
(\mu \mathrm{mol} . / \mathrm{mg} \cdot / \mathrm{hr} .)\end{array}$ \\
\hline L-Glutamic acid & 245 & $0 \cdot 97$ & $6 \cdot 5$ & $1 \cdot 85$ \\
\hline L-Aspartic acid & $\mathbf{5 0}$ & $0 \cdot 2$ & $1 \cdot 35$ & $0 \cdot 385$ \\
\hline DL-Proline & 130 & $0 \cdot 306$ & $1 \cdot 73$ & 0.49 \\
\hline DL-Serine & 70 & $0 \cdot 33$ & $1 \cdot 57$ & $0 \cdot 448$ \\
\hline DL-Alanine & 80 & $0 \cdot 318$ & 1.55 & $0 \cdot 44$ \\
\hline
\end{tabular}

Cells from Cohen \& Wheeler's medium made up to $4 \mathrm{mg}$. $/ \mathrm{ml}$. for glutamic acid and $8 \mathrm{mg}$. $/ \mathrm{ml}$. for the others.

The disappearance of glutamic acid from the medium during growth. As glutamic acid is vigorously oxidized by washed suspensions, and as it forms a large part of the amino-acid content of a casein hydrolysate, it was thought advisable to see whether it disappeared from the medium during active growth. To ensure an adequate period of logarithmic growth it was desirable to use a small inoculum, but Cohen \& Wheeler's medium, as prepared by us, would not consistently permit the growth of inocula of strain 724 smaller than $10^{6}$ cells/ $\mathrm{ml}$. and this inoculum lagged for some $12 \mathrm{hr}$. This inoculum was accordingly put into $130 \mathrm{ml}$. medium and incubated at $3^{\circ}$ on the shaker; turbidity readings, viable counts, ammonia and glutamic acid estimations were performed at intervals during growth. The results of a typical experiment are given in Fig. 2. Several points emerged from this experiment. Whereas Ungar et al. (1950) found that glutamic acid was removed from the medium during 15 day's growth, in this experiment the glutamic acid completely disappeared during the period of logarithmic growth. As might be expected, the viable count increased considerably before any decrease in the glutamic acid content of the medium could be detected by the method used for its estimation. Further, growth was beginning to slow down by the time the glutamic acid had disappeared. The total amount of ammonia produced exceeded that available from the glutamic acid, apart from the considerable amount assimilated into new cell substance.

\section{Growth in amino-acid mixtures}

From the preceding results it seemed that $\boldsymbol{H}$. pertussis might grow in a medium containing glutamate as the main source of energy, carbon and nitrogen. Accordingly, media were prepared to Cohen \& Wheeler's (1946) formula, but the Casamino acids were replaced by pure amino-acids. Horn, 
Jones \& Blum (1946) described a mixture of amino-acids designed to simulate a casein hydrolysate. As their medium contained $3 \mu \mathrm{mol}$. of glutamic acid per ml. and Cohen \& Wheeler's medium contained $8-9 \mu \mathrm{mol}$. the amounts of the

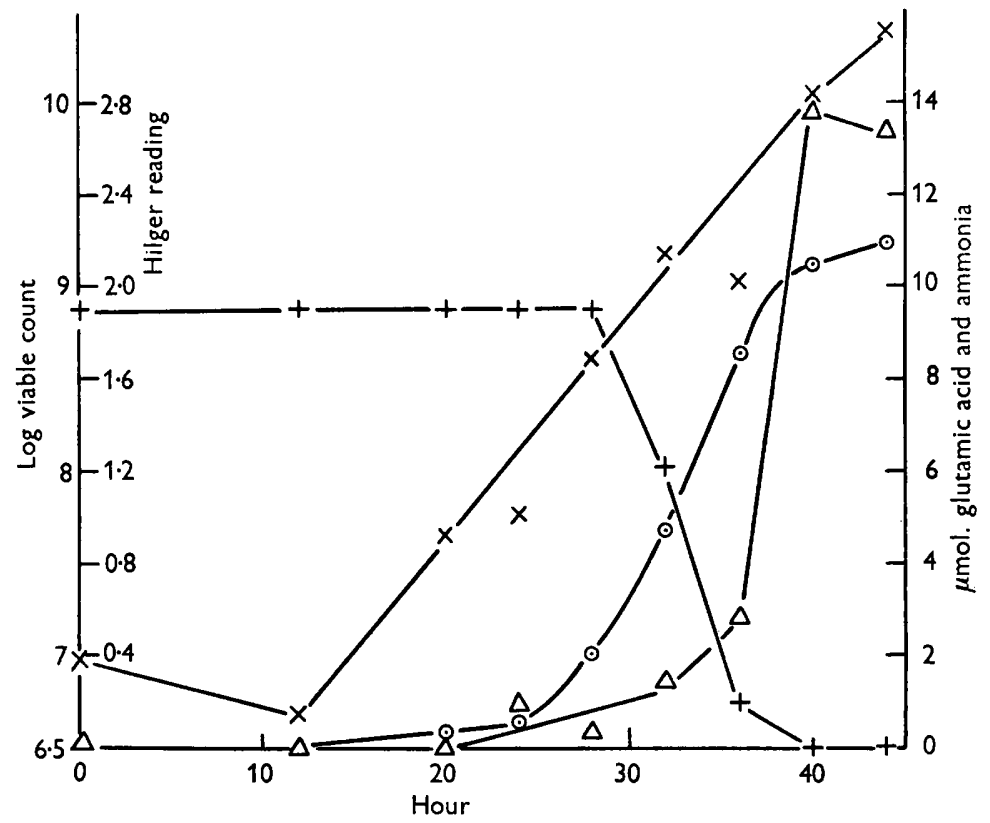

Fig. 2. Growth and utilization of glutamic acid by strain 724. $\times-\times, \log$ viable count; $\odot-\odot$, Hilger reading; $\Delta-\Delta$, ammonia content of medium; +-+ , glutamic acid content of medium.

Table 6. Growth of strain 724 in amino-acid mixtures

\begin{tabular}{|c|c|c|c|c|c|}
\hline & $\boldsymbol{A}$ & $B^{*}$ & C & $D$ & $\mathbf{E}$ \\
\hline Basal medium (ml.) & 100 & 100 & 100 & 100 & 100 \\
\hline Casamino acids (g.) & . & $1 \cdot 0$ & . & . & . \\
\hline L-Glutamic acid (mg.) & ${ }^{\circ}$ & . & 141 & . & 141 \\
\hline DL-Alanine (mg.) & . & . & . & 24 & 24 \\
\hline L-Aspartic acid (mg.) & . & . & . & 36 & 36 \\
\hline L-Proline (mg.) & • & ${ }^{\circ}$ & • & 42 & 42 \\
\hline DL-Serine (mg.) & . & . & . & 72 & 72 \\
\hline Growth at $24 \mathrm{hr}$. & - & ++ & + \pm & \pm & + \\
\hline Extinction at $48 \mathrm{hr}$. & 0.01 & 1.54 & $0 \cdot 70$ & $0 \cdot 20$ & $0 \cdot 64$ \\
\hline
\end{tabular}

Basal medium: salts, starch, cysteine and yeast dialysate as in Cohen \& Wheeler's medium.

Inoculum: approx. $10^{7}$ washed cells.

* Cohen \& Wheeler's medium.

L-isomers were trebled and five media were prepared as shown in Table 6 and distributed in $10 \mathrm{ml}$. lots in $100 \mathrm{ml}$. conical flasks. It was hoped that the yeast dialysate would provide essential amino-acids and growth factors. For the inoculum, strain 724 was washed off Bordet \& Gengou's medium with 
quarter-strength Ringer, the cells were spun off and resuspended in quarterstrength Ringer. The flasks were incubated on the shaker at $35^{\circ}$, the growth was recorded at $24 \mathrm{hr}$. and the densities of the cultures were read in a Hilger 'Biochem' absorptiometer at $48 \mathrm{hr}$. The results show that glutamate did support good growth and that the other amino-acids, in the proportions used, were not so effective. That growth in the glutamic acid medium was not so good as that in the medium containing Casamino acids was to be expected, but it was surprising that the addition of four other amino-acids to the glutamic acid medium decreased rather than increased the growth. In view of the findings of Dawson et al. (1951), it may be that the amount of serine added was inhibitory. This will be investigated later in a study of the nutrition of this organism.

\section{DISCUSSION}

This study was undertaken to determine the broad catabolic pattern of $H$. pertussis, and caution is necessary in relating these results obtained in washed suspension to the behaviour of the growing organism. Further, since $\boldsymbol{H}$. pertussis is prone to variation in laboratory subculture, it must be stressed that most of the work was done with a laboratory strain. When tested towards the end of the investigation however, it showed moderate to high virulence. Also some experiments were confirmed with several fresh strains.

With these reservations in mind the following conclusions seem justified. $\boldsymbol{H}$. pertussis is remarkably inactive towards carbohydrates and, as it does not oxidize or ferment starch, the ability of this substance to promote growth under certain conditions must presumably be due to a detoxifying action as suggested by Pollock. On the other hand, $H$. pertussis has a vigorous amino-acid metabolism and four of the acids most rapidly oxidized are those which Ungar et al. found to be removed from the medium. They also found that glycine was removed from the medium, but our strain did not oxidize it. The erratic behaviour of suspensions oxidizing aspartic acid suggests that the enzymes or co-enzymes concerned are labile and the aspartic acid metabolism of growing cells may be much more vigorous than our results suggest.

The fact that adding yeast dialysate increased the rate of oxidation of glutamate by cells grown in medium VI suggests that they were deficient in some factor which could be supplied by yeast. Cells from Cohen \& Wheeler's medium did not show this phenomenon which seems to indicate a connexion between the rate of glutamate oxidation and the adequacy of the medium. It is hoped to investigate this effect further when the nutrition, and in particular the growth-factor requirements, of $\boldsymbol{H}$. pertussis have been studied.

Glutamic acid stands out as the acid most rapidly metabolized by cell suspensions, both as measured by oxygen uptake and by ammonia production, and as the only one with which oxidative assimilation occurred. Cells which readily oxidized glutamate were much less active towards a number of compounds which might well be intermediates in the oxidation of glutamate. Krampitz \& Werkman (1941) showed that oxaloacetate cannot enter intact cells of Micrococcus lysodeikticus and if $\alpha$-ketoglutarate enters $\boldsymbol{H}$. pertussis 
with difficulty it might be admitted as an intermediate despite its slow oxidation. Slow diffusion into the cells might also explain the failure to oxidize oxaloacetate and the slow oxidation of pyruvate. The isolation of $\alpha$-ketoglutarate from suspensions metabolizing glutamic acid in the presence of arsenite supports the suggestion that it is an intermediate. With neither glutamic acid nor aspartic acid did we find any accumulation of acetic acid, which is in contrast with Klein's findings with H. parainfluenzae.

The rapid disappearance of glutamic acid from the medium during growth and the growth of the organism in a glutamic acid medium strengthen the contention that this amino-acid is probably the principal energy source of the organism, and can possibly serve as sole carbon and nitrogen source, as it does for Brucella abortus (Gerhardt, Tucker \& Wilson, 1950) and Clostridium tetanomorphum (Barker, 1939).

We are indebted to Mr H. A. Tarr for technical assistance.

\section{REFERENCES}

Adler, E., Hellström, V., Günter, G. \& Euler, H. v. (1938). Über den enzymatischen Abbau und Aufbau der Glutaminsäure. Hoppe-Seyl. Z. 255, 14.

BARKER, H. A. (1939). The use of glutamic acid for the isolation and identification of Clostridium cochlearium and Cl. tetanomorphum. Arch. Mikrobiol. 10, 376.

Bordet, J. \& Gengou, O. (1907). Note complémentaire sur le microbe de la coqueluche. Ann. Inst. Pasteur, 21, 720.

Cavaluini, D., Frontali, N. \& Toschi, G. (1949). Determination of keto-acids by partition chromatography on filter-paper. Nature, Lond., 163, 568.

Cuifton, C. E. (1946). Microbial assimilations. Advances in Enzymology, 6, 269.

Cohen, S. M. \& Wheeler, M. W. (1946). Pertussis vaccine prepared with phase I cultures grown in fluid medium. Amer. J. pub. Hlth, 36, 371.

Dawson, B., Farnworth, E. H., McLeod, J. W. \& Nicholson, D. E. (1951). Observations on the value of the Bordet-Gengou medium for the cultivation of Haemophilus pertussis. J. gen. Microbiol. 5, 408.

Evler, H. v., Adler, E. \& Eriksen, T. S. (1937). Über die Komponenten der Dehydrasesysteme. XIV. Glutaminsäure-dehydrase aus Hefe. Hoppe-Seyl. Z. 248, 227.

Farrell, L. \& Taylor, E. M. (1945). Notes on the production of phase I pertussis vaccine in fluid medium. Canad. pub. Hlth $J .36,326$.

Fildes, P. (1923). The classification of haemoglobinophilic bacteria, based upon their relation to blood-pigment and to the 'vitamine' factor. Brit. J. exp. Path. $4,265$.

GaLe, E. F. (1938). Factors influencing bacterial deamination. III. Aspartase II. Its occurrence in and extraction from Bacterium coli and its activation by adenosine and related compounds. Biochem. J. 32, 1583.

GaLe, E. F. (1945). Studies on bacterial amino-acid decarboxylases. 5. The use of specific decarboxylase preparations in the estimation of amino-acids and in protein analysis. Biochem. J. 39, 46.

Gale, E. F. \& Stephenson, M. (1938). Factors influencing bacterial deamination. II. Factors influencing the activity of DL-serine deaminase in Bacterium coli. Biochem. J. 32, 392.

Gerhardt, P., Tucker, L. A. \& Wilson, J. B. (1950). The nutrition of Brucellae: utilization of single amino-acids for growth. J. Bact. 59, 777.

Gladstone, G. P. \& Fildes, P. (1940). A simple culture medium for general use without meat extract or peptone. Brit. J. exp. Path. 21, 161. 
Honn, M. J., Jones, D. B. \& Blum, A. E. (1946). Microbiological determination of methionine in proteins and foods. J. biol. Chem. 166, 321.

Hornibrook, J. W. (1939). Cultivation of phase I $\boldsymbol{H}$. pertussis in a semi-synthetic liquid medium. Publ. Hlth Rep., Wash., 54, 1847.

Hornibrook, J. W. (1940). Nicotinic acid as a growth factor for $H$. pertussis. Proc. Soc. exp. Biol., N.Y., 45, 598.

Johnson, M. J. (1941). Isolation and properties of a pure yeast polypeptidase. J. biol. Chem. 137, 575.

KueIN, J. R. (1940). The oxidation of $1(-)$ aspartic and $1(+)$ glutamic acids by Hemophilus parainfluenzae. J. biol. Chem. 134, 43.

Krampitz, L. O. \& Werkman, C. H. (1941). The enzymic decarboxylation of oxaloacetate. Biochem. J. 35, 595.

KreBs, H. A. (1933). Weitere Untersuchungen über den Abbau der Aminosäuren im Tierkörper. Hoppe-Seyl. Z. 218, 157.

KreBs, H. A. (1948). Quantitative determination of glutamine and glutamic acid. Biochem. J. 43, 51.

Lawson, G. M. (1939). Immunity studies in pertussis. Amer. J. Hyg. 29, 119.

Mackie, T. J. \& McCartney, J. E. (1948). Handbook of Practical Bacteriology, 8th ed. Edinburgh: E. and S. Livingstone.

Markham, R. (1942). A steam distillation apparatus suitable for micro-Kjeldahl analysis. Biochem. J. 36, 790.

Pollock, M. R. (1947). The growth of $H$. pertussis on media without blood. Brit. J. exp. Path. 28, 295.

Pollock, M. R. (1949). The effects of long-chain fatty acids on the growth of Haemophilus pertussis and other organisms. Symp. Soc. exp. Biol. 3, 193.

RIVERS, T. M. (1922a). Bacterial nutrition. Growth of a hemophilic bacillus on media containing only an autoclave-stable substance as an accessory factor. Johns Hopk. Hosp. Bull. 33, 149.

RIvers, T. M. (1922b). Bacillus hemoglobinophilus canis (Friedberger). J. Bact. 7, 579.

Stamp, LoRd (1947). The preservation of bacteria by drying. J. gen. Microbiol. 1, 251.

Standfast, A. F. B. (1951). The virulence of Haemophilus pertussis for mice by the intranasal route. J. gen. Microbiol. 5, 250.

Stillman, E. G. \& Bourn, J. M. (1920). Biological study of the hemophilic bacilli. J. exp. Med. 32, 665.

Umbreit, W. W., Burris, R. H. \& Stauffer, J. F. (1945). Manometric Techniques. Minneapolis; Burgess Publishing Co.

Ungar, J., James, A. M., Muggleton, P. W., Pegler, H. F. \& Tomich, E. G. (1950). The cultivation of Haemophilus pertussis in partially defined liquid media. J. gen. Microbiol. 4, 345.

Verwey, W. F., Thiele, E. H., Sage, D. N. \& Schuchardt, L. F. (1949). A simplified liquid culture medium for the growth of Hemophilus pertussis. J. Bact. $58,127$.

Weil-Malmerbe, H. \& Krebs, H. A. (1935). Metabolism of amino-acids. V. The conversion of proline into glutamic acid in kidney. Biochem. J. 29, 2077.

Wrlson, R. J. (1945). The production of phase I pertussis vaccine in casein hydrolysate broth. Canad. publ. Hlth J. 36, 321.

Winslow, C.-E. A., Broadhurst, J., Buchanan, R. E., Krumwiede, C., Rogers, L. A. \& Sмiтн, G. H. (1920). The families and genera of the bacteria. Final report of the Committee of the Society of American Bacteriologists on characterization and classification of bacterial types. J. Bact. 5, 191.

(Received 13 May 1951) 